\title{
El nuevo Directorio para la catequesis: las motivaciones para su realización e historia de su composición y redacción
}

Miguel López Varela'

\section{Resumen}

El nuevo Directorio para la catequesis está en continuidad dinámica con los dos anteriores. Se publica tras doce borradores y un arduo proceso de elaboración de casi seis años, el más largo de los tres Directorios posconciliares. Este artículo estudia los orígenes del actual Directorio y el itinerario de su elaboración. Particularmente, se presentan los motivos y razones que lo originaron, lo que podríamos considerar la pre-historia del documento, distinguiendo entre las motivaciones de fondo y los antecedentes próximos e inmediatos; así como las tres etapas fundamentales que marcan la historia de su composición, redacción y, finalmente, publicación.

\section{Palabras claves:}

Directorio para la catequesis, historia, redacción, motivaciones, nueva evangelización

Este artículo estudia el origen del actual Directorio para la catequesis (DC). Particularmente, se abordarán los motivos y razones que lo originaron, que podaríamos considerar como su pre-historia; así como los pasos que se han dado para su composición, redacción y finalmente publicación del mismo, la historia de la redacción del texto.

\section{Introducción}

El nuevo DC no surge como un aerolito caído del cielo. Como se puede leer en su Presentación, "este Directorio para la catequesis está en

1 Sacerdote. Archidiócesis de Santiago de Compostela. 
continuidad dinámica con los dos anteriores”. De hecho, tratándose del tercer y último Directorio universal de la Iglesia para la catequesis - Directorio catequístico general (DCG) ${ }^{3}$ y el Directorio General para la Catequesis (DGC) ${ }^{4}$, el DC puede ser considerado como el hermano menor de la familia de los tres Directorios post-conciliares. En cierto modo, sus historias particulares y los eventos que la integran, constituyen los antecedentes remotos del actual Directorio.

Pero, correlativamente, los últimos eventos eclesiales ocurridos desde entonces, con sus respectivos hitos catequísticos, así como el Magisterio reciente sobre la catequesis y la evangelización, representan los antecedentes próximos e inmediatos. En ellos podemos identificar las diversas y plurales motivaciones y razones que originaron el proceso de composición y de redacción del nuevo Directorio.

\section{Motivaciones y razones para la reelaboración del DC}

Las motivaciones que subyacen a la elaboración-composición y redacción del nuevo DC son de diverso orden:

- Socio-culturales y teológico-eclesiales, que son las motivaciones de fondo;

- Histórico-eclesiales, las cuales constituyen los antecedentes próximos;

- Histórico-catequéticas, o los antecedentes inmediatos.

2 DC, Presentación, 9.

3 Sagrada Congregación para el Clero, Directorio General de Pastoral Catequética. Edición bilingüe del Directorium Catechisticum Generale, Madrid 1981, 2 ed. Para referirnos a él emplearemos las siglas del título original latino seguido del año (DCG1971). En España, el término "catequístico" del título original latino ("Directorium Catechisticum Generale") fue traducido en la edición española impresa por el giro lingüístico "pastoral catequética". En cambio, en la versión electrónica actual se opta por la traducción literal ("Directorio Catequístico General"): El Diccionario de la lengua española de la Real Academia Española recoge "catequístico" y "catequético" como términos intercambiables. Por su parte, el actual Directorio introduce una "Nota del editor" que establece una distinción entre ambos términos: "cuando decimos "Catequética" entendemos la reflexión sobre la catequesis y cuando decimos "Catequística" entendemos la acción de la catequesis" (DC, Introducción, 24, n. 4).

4 Congregación para el Clero, Directorio General para la Catequesis, Madrid 1997. 


\subsection{Las motivaciones de fondo: razones culturales y teológico-eclesiales}

En la conferencia de prensa de presentación del nuevo DC, así como en la Presentación de su edición impresa, Mons. Rino Fisichella, Presidente del PCPNE, señalaba dos requisitos específicos para la realización de este nuevo Directorio. Los precisaba posteriormente en un artículo ${ }^{5}$. Se refiere, por un lado, a una motivación cultural focalizada en el gran desafío de la cultura digital - y, por otro, a una motivación de tipo teológico y eclesial, consistente en la necesidad de seguir los caminos sinodales emprendidos por la Iglesia en los últimos quince años, tanto a nivel universal como local, e integrar las reflexiones y aportaciones del vasto y rico magisterio producido.

\subsubsection{La cultura digital y la globalización}

En efecto, como había ocurrido con los dos primeros Directorios 6 la actual edición respondía a la necesidad de una revisión y actualización del precedente texto. Las razones específicas para ello, según indicaba R. Fisichella, son de tipo pastoral y evangelizador? Había que actualizar el viejo texto de 1997 según la nueva situación eclesial y ajustarlo a las necesidades y problemáticas de los nuevos escenarios sociales y culturales. De manera particular se refiere a la nueva cultura digital y al consiguiente complejo fenómeno de la globalización de la cultura, que traen consigo consecuencias de tipo antropológico que afectan a los procesos tanto de aprendizaje como de socializacións.

5 R. Fisichella, "Presentación" en Directorio para la catequesis, Edice, Madrid, 9-16.

6 DCG-1971, Introducción, 5-8; DGC, Prefacio, n. 1-3; Congregación para el Clero, El Directorio General para la Catequesis. Motivos y criterios de la revisión (14 de octubre de 1997). Sobre la carta del papa Juan Pablo II que se recoge traducida en la referencia anterior: Juan Pablo II, Lettera di Giovanni Paolo II al Cardinale José T. Sánchez in occasione della IX Sessione plenaria del Consiglio Internazionale per la Catechesi (21 de septiembre de 1994) Congregación para el Clero, Congresso Catechistico Internazionale. Comunicazioni finali (17 de octubre de 1997).

7 R. Fisichella, "Le motivazioni di fondo, i punti nevralgici e le parole-chiave nella tessitura del nuovo Direttorio per la catechesi (2020)", Salesianum 82 (2020) 614631, 617-618.

8 DC, Presentación, 12. Además Fisichella, "Presentación". 
En este sentido, el DC se hará eco de este y de otros nuevos escenarios socioculturales, que ya habían sido señalados por el Sínodo de la nueva evangelización y la transmisión de la fe (2012), así como de la correlativa urgencia de la inculturación de la fe en los mismos?.

\subsubsection{El camino sinodal de la Iglesia}

Pero, también, el nuevo DC surge de la necesidad de integrar los avances y aportaciones del Magisterio reciente en materia de catequesis. Esta exigencia se sustenta, como indica Mons. Fisichella, en una motivación profunda, de "naturaleza teológica y eclesial", propia de este "momento de transición cultural" que vivimos ${ }^{10}$ : el mayor y progresivo redescubrimiento y conciencia en la reflexión y en la vivencia pastoral de la iglesia de "la exigencia de la evangelización" ". De ella dan testimonio los últimos Sínodos de los Obispos, lo cual, una vez más, reafirma la actual "invitación a vivir cada vez más la dimensión sinodal” en la Iglesia'².

En efecto, en las últimas asambleas del Sínodo de los Obispos ${ }^{13}$, y particularmente en los documentos que le siguieron, se pueden verificar una serie de "constantes" "que tocan de cerca el tema de la evangelización y de la catequesis"14. Precisamente, este "estrecho vínculo entre la evangelización y la catequesis es la peculiaridad de este Directorio", que "pretende proponer un camino en el que estén íntimamente unidos el anuncio del kerigma y su maduración”"15.

9 Fisichella, "Le motivazioni di fondo", 629-630.

10 Fisichella, "Le motivazioni di fondo", 618.

11 Fisichella, "Le motivazioni di fondo", 618-619.

12 Fisichella, "Presentación".

13 DC, Introducción, 6; Fisichella, "Presentación", Fisichella., "Le motivazioni di fondo", 619. Se señalan como significativos los Sínodos de La Eucaristía, fuente y cumbre de la vida y misión de la Iglesia (2005); La Palabra de Dios en la vida y misión de la Iglesia (2008); La vocación y misión de la familia en la Iglesia y en el mundo contemporáneo (2015); Los Jóvenes, la fe y el discernimiento vocacional (2018). Pero, sobre todo, marcaría el nuevo DC el Sínodo sobre la Nueva evangelización y la transmisión de la fe (2012), con la consiguiente Exhortación Apostólica del Papa Francisco Evangelii gaudium (2013).

14 Fisichella, "Presentación"; Fisichella, "Le motivazioni di fondo", 619-620.

15 DC, Presentación, 12. 


\subsection{Los antecedentes próximos: un hecho fundamental y sus acontecimientos}

En este periodo de veintitrés años desde la publicación del precedente DGC, sucedieron toda una serie de "acontecimientos importantes", los cuales no sólo "han marcado la renovación de la catequesis" sino que, de modo particular, han motivado y también acompañado la elaboración y redacción del actual $\mathrm{DC}^{16}$.

Entre éstos, en relación a la elaboración del nuevo DC destacan dos hechos sucesivos del año 2013 asociados al Sínodo de los obispos de la Nueva evangelización": la Carta apostólica en forma de "motu proprio”, Fides per doctrinam ${ }^{18}$, y la publicación de la primera Exhortación Apostólica del Papa Francisco, la Evangelii Gaudium¹9.

\subsubsection{El traspaso de las competencias sobre la catequesis al PCPNE}

La Fides per doctrinam supuso la transferencia de las competencias en materia de catequesis desde la Congregación para el Clero al PCPNE, por entonces recientemente constituido (2010) ${ }^{20}$. De esta manera, el papa actual emérito, Benedicto XVI, que durante su pontificado "subrayó, en multitud de ocasiones, la impor-

16 DC, Introducción, 6. Además de los Sínodos de los obispos señalados, también hay que mencionar el Gran Jubileo del 2000, el Año de la Fe (2012-2013) y el Jubileo extraordinario de la Misericordia (2015-2016). Finalmente, la publicación del Compendio del Catecismo de la Iglesia Católica (2005).

17 Sínodo de los Obispos, XIII Asamblea General Ordinaria del Sínodo de los Obispos sobre La nueva evangelización para la transmisión de la fe cristiana (7-28 de octubre de 2012).

18 Benedicto XVI, Carta Apostólica en forma de "Motu proprio" Fides per doctrinam, con la que se modifica la Constitución apostólica "Pastor bonus" y se transfiere la competencia sobre la catequesis de la Congregación para el clero al Consejo pontificio para la promoción de la nueva evangelización (16 de enero de 2013).

19 Francisco, Exhortación Apostólica Evangelii Gaudium (24 de noviembre de 2013), Madrid 2013, 20-24. En adelante, EG.

20 Benedicto XVI instituía este Pontificio Consejo por medio de la Carta Apostólica en forma de "Motu proprio" Ubicumque et Semper, con la cual se instituye el Consejo Pontificio para la Promoción de la Nueva Evangelización (21 de septiembre de 2010) Acerca de la identidad y características de este nuevo Organismo vaticano: A. Viana, "Anotaciones sobre el Consejo Pontificio para la Nueva Evangelización”, Ius Canonicum 51 (2011) 243-254. 
tancia de la catequesis en el proceso de nueva evangelización” ${ }_{21}$, cumplía un deseo que ya había expresado en una de las sesiones finales del Sínodo de los Obispos sobre la Nueva evangelización y la transmisión de la fe del 2012.

Se trata de un cambio que no respondía sólo a motivos institucionales asociados a la organización interna de la Curia Vaticana. Más bien, tenía que ver con el reconocimiento de la relación intrínseca que la catequesis guarda con la misión evangelizadora de la Iglesia, y la gran contribución que le presta ${ }^{22}$. Por este motivo, este cambio puede considerarse el hecho fundamental detrás del cual se encuentra la última edición del DC. Si el DGC era el directorio que promovió una catequesis evangelizadora, el presente DC será el directorio para la catequesis de la nueva evangelización.

\subsubsection{La carta magna que guió los trabajos del nuevo Directorio}

Tan sólo dos meses después de este hecho fundamental, el recientemente nombrado papa Francisco publicaba su primera exhortación, o carta programática de su pontificado, la EG. Para el PCPNE se convertiría en la hoja de ruta tanto de su reflexión como de sus actividades e iniciativas. De modo que, aun cuando la Evangelii nuntiandi ${ }^{23}$ continúe siendo la gran carta magna de la Evangelización, la EG pasará a ser el documento homólogo de la nueva evangelización.

Consecuentemente y, de manera particular, la EG juntamente con las reflexiones del Sínodo de los obispos de La nueva evangelización y la transmisión de la fe, se convirtieron en las fuentes magisteriales principales de inspiración y en el "criterio que ha motivado la reflexión y la redacción” del nuevo DC²4. El PCPNE asumía así el compromiso de la necesaria "conversión pastoral y misionera" de la catequesis (Cf.. EG 25, 30; 160-175).

21 DC, Introducción, 6.

22 Fisichella, "Le motivazioni di fondo", 614.

23 Pablo VI, Exhortación apostólica postsinodal Evangelii nuntiandi (8 de diciembre de 1975), Madrid 1975. En adelante, EN.

24 DC, Presentación, 11 y 13; Fisichella, "Le motivazioni di fondo", 619-620. 


\subsubsection{La actividad del PCPNE en torno a la catequesis}

Tras la recepción de las competencias en materia de catequesis, el PCPNE se empeñó esclarecer, desde el documento programático de la EG, la relación de ésta con la nueva evangelización, y en definir su identidad y la contribución que presta a la misma.

En esta línea, desde el PCPNE se desarrollaron una serie de actividades e iniciativas específicas, a la vez que se aprovecharían para el mismo fin otras actividades que ya se venían realizando en el Dicasterio. Iniciaba así, lo que podemos denominar una primera "fase de escucha, de estudio y de confrontación acerca de la realidad de la catequesis en los contextos eclesiales de los distintos continentes" (2014-2015) ${ }^{25}$.

Se organiza en primer lugar un gran Encuentro Internacional en la ciudad de Roma titulado "El proyecto pastoral de Evangelii Gaudium" (18-20 de septiembre de 2014) ${ }^{26}$. Durante tres días, expertos de todas las partes del mundo desentrañaron y expusieron el programa pastoral para la Iglesia que el papa presenta en su primer documento.

Juntamente con éste, se realizaron una serie de específicos seminarios internacionales de estudio sobre la relación entre la catequesis y la $\mathrm{EG}^{27}$. Constituyen los antecedentes próximos del DC, pues a partir de ellos se daba inicio a la redacción de un proyecto

25 Fisichella, "Le motivazioni di fondo", 616.

26 PCPNE, Encuentro Internacional "El Proyecto Pastoral de Evangelii Gaudium" (1820 de septiembre de 2014).

27 Fisichella, "Le motivazioni di fondo", 616. El primero de estos encuentros consistió en una Jornada de estudio titulada "Catequesis y nueva evangelización", celebrado el 18 de noviembre del 2014. Se desarrolla en la sede del PCPNE con el fin de establecer las aportaciones de la EG a la catequesis, y "profundizar en la comprensión de cómo la actividad catequética se inscribe en el proceso de la nueva evangelización". En ella participaron algunos profesores de ámbito europeo expertos en evangelización, pastoral y catequesis. Más tarde, en marzo de 2015, también "en Roma, hubo un seminario de estudio con expertos del mundo académico y de organizaciones pastorales en el campo de la catequesis, para aportar una visión global de la situación de la catequesis en Europa, Estados Unidos y América Latina". 
de documento titulado Catequesis y Nueva Evangelización. Éste será fundamental, como se verá, para iniciar los trabajos de revisión y posterior actualización del $\mathrm{DGC}^{28}$.

Contemporáneamente y a fin de conocer la situación real de la catequesis en las diversas partes del mundo, el PCPNE promovió una serie de encuentros internacionales con los obispos y los responsables de los departamentos de nueva evangelización y catequesis de las Conferencias Episcopales de las diferentes regiones del mundo ${ }^{29}$. Estos eventos permitieron entrar en contacto directo con algunos expertos de catequesis y conocer de primera mano la producción catequética e iniciativas catequísticas de los distintos países.

\subsection{Los antecedentes inmediatos: la concurrencia de grandes efemérides para la catequesis}

Señalamos finalmente una serie de conmemoraciones históricas en torno a la catequesis, que concurrían todas ellas en el año 2017. Todas ellas favorecieron una conciencia eclesial en torno a la catequesis, contribuyendo decisivamente a poner de actualidad el Directorio y a recuperar el interés por él y la necesidad de su renovación.

Constituyen los antecedentes más inmediatos y fueron abordadas en 2015 durante la celebración de la II Asamblea Plenaria del PCPNE (27-29 del 2015) ${ }^{30}$, en las inmediaciones de la celebración de su quinto aniversario de creación; y, sucesivamente, en la reunión que se tenía con el Consejo Internacional para la Catequesis

28 O. Ruiz Arenas, "Conferencia de presentación del Directorio para la Catequesis elaborado por el Consejo Pontificio para la Promoción de la Nueva Evangelización" (25 de junio de 2020), Fisichella, "Le motivazioni di fondo", 616.

29 Ruiz Arenas, "Conferencia". En el texto se enumeran estos encuentros: en Puebla, con los delegados de América Central, México y el Caribe (diciembre de 2014); en Roma, con los delegados de las Comisiones Episcopales para la catequesis de Europa (enero de 2015); en la ciudad de San Luis, con los representantes de Estados Unidos (junio de 2015); finalmente, dos encuentros sucesivos, en la ciudad de Aparecida para todo el Brasil, y en Lima con los delegados del Cono Sur y la Región Andina de América Latina (septiembre de 2015).

30 Ruiz Arenas, "Conferencia". 
(Co.In.Cat) ${ }^{31}$, que tenía lugar durante la tarde del 29 y toda la jornada del $30^{32}$.

\subsubsection{La celebración del quincuagésimo Aniversario de la clausura del Concilio Vaticano II}

Fue considerado por san Pablo VI como "el gran catecismo de los tiempos modernos" ${ }^{33}$. Para conmemorarlo, el papa Francisco había convocado un Jubileo extraordinario de la misericordia (8 de diciembre de 2015 - 20 de noviembre de 2016). Se trataba del primer jubileo universal temático de la historia, que tomaba pie en las palabras de la $\mathrm{EG}^{34}$. Su organización y desarrollo, confiado por el Papa al PCPNE, como se verá, influirá profundamente en los trabajos del futuro Directorio: ralentizando su marcha en algunas ocasiones, pero también propiciando algunos encuentros importantes para la catequesis; y, sobre todo, enriqueciéndolo con la inclusión de la temática de la misericordia.

31 El Co.In.Cat es un organismo consultivo creado en 1973 por el santo Papa Pablo VI. Lo integran diversos expertos en el campo de la catequesis de todo el mundo. Su objetivo es promover el intercambio de experiencias, estudiar los temas catequéticos más importantes al servicio de la Sede Apostólica y de las Conferencias Episcopales, para presentar propuestas y sugerencias. Hasta el 2013 este organismo dependía de la Congregación para el Clero. A partir de entonces, por la Carta Apostólica de Benedicto XVI en forma "Motu Proprio" Fides per doctrinam, pasaba a depender, junto con las competencias en materia de catequesis, del PCPNE. Actualmente está compuesto por 14 miembros. Entre ellos hay obispos, sacerdotes y laicos, provenientes de todas las partes del mundo: India, México, Reino Unido, Francia, Perú, Ucrania, Alemania, Polonia, Italia, EE.UU., Tanzania, España y Brasil. Todos ellos prestan ayuda al actual "Dicasterio competente a dar a conocer las peticiones de las diversas Iglesias para que la catequesis se adapte cada vez más al tejido eclesial, cultural e histórico" (DC, Presentación, 10). Tras expiar su mandato, en este momento el organismo se encuentra en fase de renovación de sus miembros: PCPNE, Consejo Internacional de Catequesis (COINCAT) (30-05-2015).

32 PCPNE, Consejo Internacional de Catequesis (COINCAT).

33 Pablo VI, Discurso a los miembros de la I Asamblea General de la Conferencia Episcopal Italiana (23 de junio de 1966), tomado de: DC, Presentación, 10.

34 EG 24: "La Iglesia en salida es la comunidad de discípulos misioneros que primerean" y "vive un deseo inagotable de brindar misericordia, fruto de haber experimentado la infinita misericordia del Padre y su fuerza difusiva". 


\subsubsection{Los aniversarios específicos para la catequesis}

En el año 2017 concurrían una serie de conmemoraciones importantes para la historia reciente de la catequesis. Por un lado, el XL Aniversario del Sinodo de los Obispos sobre la catequesis en nuestro tiempo (30 de septiembre-29 de octubre de 1977) y que daría como fruto la Exhortación apostólica sobre la catequesis en nuestro tiempo, Catechesi tradendae (1979).

Otras dos conmemoraciones importantes para la catequesis se remontan a finales de la década de los noventa, que fue riquísima para la catequesis ${ }^{35}$. Concretamente, se recuerdan el XX Aniversario del DGC (15 de agosto), y el XXV Aniversario de la de la presentación de la edición típica del Catecismo de la Iglesia Católica (8 de septiembre) ${ }^{36}$.

\subsubsection{El proyecto del documento Catequesis y Nueva Evangelización}

Pero sin duda ninguna, el hecho más relevante para iniciar los trabajos del nuevo DC tiene que ver con la presentación del mencionado documento Catequesis y Nueva Evangelización a los miembros de la Asamblea plenaria y del Co.In.Cat. En mayo de 2015 se había elaborado el primer borrador a partir del DGC, asumiendo todas

35 En la historia reciente de la catequesis, la década de los noventa fue muy prolija en documentos. Señalamos dos documentos eclesiales más de especial relevancia: Co.In.Cat, La catequesis de adultos en la comunidad cristiana. Algunas líneas y orientaciones, Ciudad del Vaticano 1990; Congregación para la Evangelización de los Pueblos, Guía para los catequistas, Ciudad del Vaticano 1993.

36 La aprobación de la edición típica latina, en cambio, ya había sido hecha el 15 de agosto: v. Juan Pablo II, Carta apostólica Laetamur magnopere, por la que se aprueba la edición típica latina del Catecismo de la Iglesia Católica (15 de agosto de 1997). La relación entre el PCPNE y el Catecismo de la Iglesia Católica, en adelante, CCE, se remontaba al año 2012, cuando en contexto del Año de la fe (11 de octubre de 2012 -24 de noviembre de 2013), y con el fin de promover el conocimiento y el empleo del CCE como instrumento para la nueva evangelización, se celebra el I Congreso Internacional de Catequesis (Roma, 26-29 septiembre 2013). Bajo el título "El Catequista, testigo de la fe", se afrontó entonces el estudio de su primera parte ("La profesión de fe"). Cinco años después, el PCPNE organizará el II Congreso Internacional de Catequesis (Roma, 20-23 de septiembre de 2018), bajo el título "El Catequista, testigo del misterio", y en el que se estudiaría la segunda parte del CCE ("La celebración del misterio cristiano"). 
las indicaciones pastorales y catequéticas del papa Francisco en la exhortación apostólica $E G$.

Teniendo en cuenta estas importantes celebraciones para la catequesis y la evangelización, al término de los trabajos de ambos encuentros, se acordaba que era oportuno hacer una relectura del $D G C-1997$, con el fin de ofrecer una edición revisada y actualizada a los nuevos tiempos ${ }^{37}$. Se sugería que se incluyese en ella la perspectiva misionera de la catequesis recogida en el documento presentado, pero también, un desarrollo temático sobre el primer anuncio. De este modo, se pretendía dar respuesta a la solicitud de elaborar un Directorio sobre el primer anuncio que algunos padres sinodales habían realizado durante la III Asamblea General Extraordinaria del Sínodo de los Obispos sobre la familia ${ }^{38}$.

\section{Historia de la composición y redacción del DC}

El proceso de elaboración y redacción del nuevo DC no fue muy distinto al seguido en los dos anteriores ${ }^{39}$. Los trabajos fueron todos orientados y supervisados por el PCPNE y su equipo, que con la recepción de las competencias para la catequesis, había creado una pequeña sección dentro del Dicasterio dedicada a los temas de catequesis.

Este arduo proceso de elaboración duró casi seis años, el más largo de los tres Directorios, y llegaba a su fin tras doce borradores ${ }^{40}$. Este camino tampoco estuvo exento de dificultades: las propias de este tipo de obras; pero también debidas al método "sinodal" seguido para la escucha de las Iglesias particulares; y, finalmente, causadas por los avatares del propio PCPNE, que en este periodo tuvo que asumir la organización de diversos eventos eclesiales de gran calado, como es el Jubileo de la Misericordia.

37 Ruiz Arenas, "Conferencia".

38 Sínodo de los Obispos, la III Asamblea General Extraordinaria del Sínodo de los Obispos sobre Los desafíos pastorales de la familia en el contexto de la evangelización (5-19 de octubre de 2014).

39 DCG-1971, Introducción, 5-6; G. Biancardi, "Genesi e sviluppo storico del genere Direttorio catechistico", Salesianum 82 (2020) 654; DGC, Prefacio, n. 7.

40 Ruiz Arenas, "Conferencia”. 
En todo este proceso pueden señalarse tres etapas fundamentales. La formulación de las mismas pretende servir para mostrar, antes que nada, el dinamismo y la evolución que fueron siguiendo los trabajos.

\subsection{Fase de relectura para una revisión y actualización del DGC (2016-2017): primeros trabajos}

Esta primera etapa abarca, prácticamente, todo el periodo jubilar (2015-2016). Está marcada por los trabajos de la Comisión de doce expertos a nivel mundial que el PCPNE creaba para examinar el DGC y hacer propuestas de actualización.

\subsubsection{Los trabajos de la Comisión de expertos}

Para dar continuidad a los acuerdos tomados en la Plenaria y en el Co.In.Cat, con el fin de examinar el DGC y recabar propuestas para su actualización, el PCPNE decide constituir una Comisión internacional de doce expertos catequetas. La comisión se reunió en Roma en tres ocasiones durante el año 2016, y en ellas participaron también "los superiores del Consejo Pontificio, un obispo de las Iglesias Orientales, seis sacerdotes, una religiosa, tres laicas y un laico" ${ }^{41}$.

En la primera de las sesiones (2-3 de marzo), se examinó el DGC-1997 con la idea de hacer una relectura y revisión del mismo. Para ello se establecieron tres criterios de trabajo42: identificar los elementos que todavía siguen siendo válidos (fortalezas); señalar los puntos más críticos y que necesitan ser revisados, ampliados o actualizados (limites); indicar y sugerir los puntos y temáticas novedosas en el campo de la catequesis que deberían ser introducidas (carencias).

Durante el encuentro, el sentir mayoritario de los expertos era que el DGC era un gran documento, en muchos casos todavía por descu-

41 Ruiz Arenas, "Conferencia”. Los expertos provenían del Brasil, Colombia, México, Estados Unidos y varios países europeos (Croacia, Francia, Italia, Polonia, Reino Unido, España y Ucrania).

42 En el DGC se habían indicado algunos "criterios teológico-pastorales" para la "revisión" y "redacción del Directorio General para la Catequesis y la organización de sus partes": v. Congregación para el Clero, El Directorio General para la Catequesis. Motivos y criterios de la revisión (14 de octubre de 1997). 
brir. Pero que, por otra parte y, debido al tiempo transcurrido desde su publicación y a los cambios que se habían producido desde entonces, precisaba de una revisión y una actualización de algunos aspectos y puntos ${ }^{43}$.

Al final de este primer encuentro, se estableció un programa de trabajo para los próximos meses. Se acordó que cada uno de los miembros de la Comisión, siguiendo los criterios indicados, trabajaría de forma remota en una de las partes, o sobre algunos números, según la especialidad de cada uno.

La segunda sesión (6-7 de julio), serviría para poner en común los trabajos que cada miembro había realizado y compartir las diversas sugerencias. Tres meses después tenía lugar el tercer y último encuentro (24 y 28 de octubre). En él se revisó y discutió de manera global el texto trabajado del DGC hasta el momento, introduciendo ulteriores correcciones y temáticas ${ }^{44}$. Se concluía que era insuficiente la realización de una revisión y actualización textual del DGC. Se precisaba hacer una renovación y reforma profunda, que incluye un nuevo ordenamiento de todo y una nueva estructura, para responder de manera más directa a los desafíos que enfrenta hoy la Iglesia; teniendo en cuenta los grandes cambios culturales que han tenido lugar en los últimos años y, también, el rico magisterio pontificio de este período ${ }^{45}$.

43 La comisión señaló los siguientes: asumir las aportaciones de la $E G$ y del resto del magisterio posterior al DGC sobre la catequesis y la evangelización; introducir algunas temáticas específicas relativas a la nueva evangelización (la opción misionera de la Iglesia; anuncio misionero y kerigma, etc.); extraer algunas partes y números ya superados; purificar el lenguaje y algunas expresiones. Además, la Comisión sugirió la revisión de algunos temas específicos, como son la naturaleza catecumenal e iniciática de la catequesis, la referencialidad y normatividad para la catequesis del CCE; la Pedagogía divina en la catequesis; los nuevos ámbitos y escenarios de la catequesis, etc. Por su parte, el PCPNE compartió con los miembros de la Comisión otros temáticas que se habían tratado en su anterior II Asamblea Plenaria así como con los miembros del Co.In.Cat, y sobre los que venía investigando y reflexionando durante los últimos años: la relación entre el primer anuncio o kerigma y la catequesis, y la eventual institución del ministerio del catequista para toda la Iglesia.

44 Ruiz Arenas, "Conferencia".

45 Ruiz Arenas, "Conferencia". 
Al mismo tiempo, durante este periodo y, desde el interior del PCPNE, se contactó al Cardenal José Manuel Estepa LIaurens' ${ }^{46}$ y al profesor Cesare Bissoli, dos de los expertos que habían trabajado más directamente en la elaboración y redacción del anterior $\mathrm{DGC}^{47}$, para preguntarles acerca del procedimiento que se había seguido en su elaboración. Además, se les consultó acerca de los temas que entonces habían quedado pendientes de desarrollo y sus puntos débiles.

\subsubsection{Las aportaciones del Jubileo extraordinario de la misericordia}

En no pocas ocasiones el Jubileo extraordinario de la Misericordia sirvió de freno para los trabajos del Directorio. Sin embargo, hay que decir que aún así, este Jubileo supuso al Directorio un gran impulso en su reflexión sobre la relación entre la catequesis y la NE. Prueba de ello es la consideración que en el nuevo DC tiene la misericordia como uno de los "acentos" propios de la catequesis en este tiempo de nueva evangelización (DC 51-52).

Por otro lado, el Jubileo también ejerció una positiva influencia indirecta en los trabajos del nuevo DC. Muchos de los trabajos, encuentros, reuniones preparatorias para este jubileo, a los que asistían distintos invitados - expertos y especialistas en los diversos campos de la catequesis, pero también responsables de catequesis de las conferencias episcopales, catequistas de base, etc. -, eran también aprovechados para realizar consultas y recabar información sobre las temáticas y los aspectos concretos que tendrían que abordarse e incluirse en un futuro documento de estas características.

Dentro del Año Jubilar, tres eventos resaltan de manera especial por la influencia que han dejado en el DC:

46 Dentro del programa de las XXXV Jornadas Nacionales de la Asociación Española de Catequetas (AECA), tituladas Directorio General para la Catequesis. 20 años (Madrid, 5-7 diciembre de 2015), y con motivo de la publicación de la monumental obra (1415 páginas) de los escritos del Cardenal José M. Estepa, La catequesis en la misión de la Iglesia. Escritos catequéticos 1960-2010, BAC, Madrid 2015, se tuvo un encuentro y un diálogo con el Cardenal entorno a su implicación en el DGC. AECA, Boletín informativo, 67 (2016) 10.

47 Congregación para el Clero, Actualización del Directorio Catequístico General (14 de octubre de 1997). Biancardi, "Genesi e sviluppo", 633-655. 
- El Jubileo de los catequistas (23-25 de septiembre de 2016), que visibilizó una vez más la gran fuerza y vida que los catequistas suponen para la Iglesia y su misión. Este hecho estimuló y animó los trabajos del nuevo Directorio.

- El I Encuentro de los Consejos Directivos de Catequetas del mundo (21-23 de septiembre), celebrado en Roma durante el Jubileo de los catequistas y apoyado por el PCPNE ${ }^{48}$. Este evento contribuyó a un mayor conocimiento de la problemática de la catequesis en el mundo y al intercambiar de pareceres con respecto a algunas temáticas que se estaban abordando en los trabajos de revisión del DGC ${ }^{49}$.

- El Jubileo de los enfermosy las personas con diversidad funcional (10-12 de junio de 2016), que enriquecería los números del DC dedicados a las personas con discapacidad (DC 269-272). Esta hermosa experiencia jubilar, y las palabras del santo Padre de esos días, motivarían la organización del $I$ Congreso internacional "Catequesis y personas con discapacidad. Una atención necesaria en la vida diaria de la Iglesia” (Roma, 20-22 de octubre de 2017). Del mismo modo el Jubileo de los reclusos (6 de noviembre de 2016), con explícitas resonancias en el futuro texto del Directorio (DC 281-282).

\subsection{Fase de reforma, actualización temática y reestructuración del DGC (2017): primeros borradores}

Nos encontrarnos en la fase en la que se produjeron los cuatro primeros borradores, los cuales constituirán la base textual de futuro DC. Todavía no se puede hablar, en sentido estricto, del texto de un nuevo Directorio, ya que la opción de fondo continúa siendo la de realizar una edición revisada y actualizada a partir del viejo texto.

48 Participaron en él una quincena de representantes de las asociaciones de SCALA, la Asociación Española de Catequetas (AECA), la Asociación Italiana de Catequetas (AICA) y del Equipo Europeo de catequesis (EEC). El proyecto de reunirse en Roma los miembros de las Asociaciones de catequetas de todo el mundo surgía en la ciudad de Lima, durante el encuentro referido del PCPNE con los delegados del Cono Sury la Región Andina de América Latina (7-9 de septiembre de 2015). Este primer encuentro sirvió para establecer relaciones entre las distintas sociedades. Recientemente se celebraba un "Encuentro Iberoamericano" online entre los miembros de SCALA y AECA, que contó también con la presencia de algunos catequetas de Portugal, para hacer una lectura y reflexión conjunta sobre el nuevo DC. Posteriormente se hacía una publicación de formato digital y de acceso abierto con las diez principales colaboraciones (SCALA-AECA, Encuentro Iberoamericano de Catequetas 2020, Providencia 2020).

49 AECA, Boletín informativo, 68 (2016) 6. 
La conclusión del Jubileo de la misericordia permitió dedicar más tiempo a estas tareas, y contribuyó notablemente a acelerar el ritmo de los trabajos. Aunque éste se vio por veces ralentizado debido a la organización y realización de diversas actividades previstas en el calendario - el XXV Aniversario de la edición típica del CCE y el II Congreso Internacional de Catequesis -; así como a la asunción de las nuevas competencias sobre los Santuarios y la consiguiente responsabilidad sobre la promoción de la pastoral de la piedad popular y de las peregrinaciones a los lugares de culto ${ }^{50}$, hasta el momento pertenecientes a la Congregación para el Clero.

\subsubsection{El primer borrador del Directorio}

Durante los meses que siguieron al último encuentro de la Comisión de expertos, el PCPNE se encargaría de introducir en el texto revisado del DGC todas sus indicaciones, y también de estudiarlo con detenimiento. De este modo, se simplificaron apartados y se extrajeron textos desfasados; se introdujeron nuevos temas; se actualizó el lenguaje y se aligeró la redacción. Es así como se llegó, a finales del año 2016, a la redacción de un primer anteproyecto.

Este primer texto - que sustancialmente mantenía la misma estructura del DGC, pero a la vez reflejaba las conclusiones alcanzadas por los expertos durante las tres sesiones -, serviría de base al PCPNE para la preparación del primer borrador del futuro $D^{51}$. El documento sería sometido una vez más, por correspondencia, al parecer de los miembros de la comisión de expertos, así como al de otros peritos y especialistas; los cuales enviarían sus observaciones, y nuevamente serían estudiadas y eventualmente introducidas en el texto.

En abril de 2017, el primer borrador era enviado a más de cien expertos de los cinco continentes. Entre ellos se encontraban cardenales, obispos, sacerdotes, religiosos, religiosas y laicos competen-

50 Francisco, Carta Apostólica en forma de "Motu proprio" Sanctuarium in Ecclesia, con la que se transfieren las competencias sobre los santuarios al Consejo Pontificio para la Promoción de la Nueva Evangelización (1 de abril de 2017).

51 Ruiz Arenas, "Conferencia". 
tes en Sagrada Escritura, teología, catequesis, liturgia y teología pastoral. Asimismo, se consultaron varias Conferencias Episcopales y Universidades, así como los miembros del Co.In.Cat. ${ }^{52}$.

\subsubsection{Elaboración de los borradores II y III}

Con esta primera y amplísima consulta, comenzaba para el PCPNE una etapa de minucioso, intenso y complejo trabajo que, tras casi veinte sucesivas redacciones, llevarían a la elaboración del segundo borrador.

Las abundantes y plurales observaciones recibidas tras la consulta, fruto de la gran diversidad de contextos, acentuaciones, preocupaciones, problemáticas, necesidades y retos de las Iglesias particulares, fueron todas ellas tomadas en consideración. La dificultad de integrar la riqueza de todas las aportaciones que iban llegando impuso al PCPNE un lento ritmo de elaboración y redacción, que se prolongó durante tres meses. Una por una, éstas iban siendo examinadas; valoradas individualmente y conjuntamente en reunión plenaria dentro del PCPNE; y, posteriormente, meticulosamente introducidas en el borrador presentado, que iría modificándose progresivamente hasta alcanzar su décima versión.

Los resultados de la amplitud de esta primera consulta, venían a sumarse a los datos ya conocidos por el PCPNE a través de los encuentros internacionales promovidos entre los años 2014 y 2015, tanto a nivel de reflexión catequética como de actividad catequística en los distintos continentes. Se logró tener así un mapa más amplio de la inmensa riqueza y amplia diversidad de las iglesias en relación a la evangelización, la nueva evangelización y la catequesis. Detrás de una difusa y común conciencia sobre la urgencia de la nueva evangelización, las prioridades y necesidades, los matices y los acentos concretos eran muy variados.

El segundo borrador vendría posteriormente examinado y discutido dentro del PCPNE durante el período estivo de 2017. El resultado de estos trabajos es un tercer borrador, sobre el que se continuó trabajando. Fundamentalmente se introdujeron las aportaciones que iban llegando de los ulteriores pareceres pedidos a algunos especialistas. Se 52 Ruiz Arenas, "Conferencia”. 
habían realizado una serie de nuevas consultas en relación a ciertos temas todavía pendientes de matizar, y también sobre otras posibles temáticas que, según el parecer experto de los mismos, tendrían que incluirse y abordarse en un documento de estas características. Fruto de este periodo son las abundantes contribuciones recibidas sobre la catequesis en los distintos escenarios y contextos socio-culturales contemporáneos, que en el nuevo documento encontrarán un amplio tratamiento (v. DC, Cap. X, 319-393).

Al final del verano, con el transfundo de las recientes nuevas competencias adquiridas sobre los santuarios, y el anuncio de la celebración del próximo Sínodo de los obispos sobre los jóvenes (3-28 de octubre de 2018), "en septiembre de 2017 se celebró un encuentro con los consultores del Consejo Pontificio para la Promoción de la Nueva Evangelización durante el cual hubo una reflexión especial sobre el tema de los jóvenes y de la piedad popular, cuestiones importantes en la preparación del propio Directorio" ${ }^{53}$.

\subsubsection{Aprobación del IV borrador por la IV Asamblea Plenaria del PCPNE}

Un nuevo borrador, el cuarto, sería enviado a los Miembros y Consultores del Dicasterio. Se trataba de un documento con una estructura muy similar al texto definitivo del nuevo DC. Los trabajos precedentes llevaron a incorporar progresivamente algunas variaciones a nivel de estructura general que ahora se materializaban. Los cambios más notables con respecto al anterior documento, todos ellos fruto de controversia y discusión entre los expertos, tienen que ver con la colocación de las temáticas del catequista y su formación, que pasan a la primera parte, y con el posicionamiento del CCE, que se sitúa al final de la segunda parte. Éstas y otras temáticas más novedosas, no lograrían aún su colocación definitiva.

Este cuarto borrador fue discutido posteriormente en la IV Asamblea Plenaria del PCPNE, reunida durante los días del 27 al 29 de septiembre del 2017. En el transcurso de la misma, se reflexionó también sobre los temas de los jóvenes y de la piedad popular; cuestiones que eran con-

53 Ruiz Arenas, "Conferencia”. Sobre los miembros consultores PCPNE, Pontificio Consejo. Miembros y Consultores. 
sideradas importantes en la preparación del nuevo texto del Directorio. Se concluiría con la aprobación, "en sustancia", del cuarto borrador del Directorio por parte de sus miembros ${ }^{54}$.

Por su parte, los preparativos para la celebración del XXV Aniversario de la edición típica del CCE (1l de octubre de 2017), supusieron un nuevo freno a los trabajos del nuevo texto del DC. Pero a la vez y, exactamente igual a como había sucedido con el Jubileo de la misericordia, proporcionaron también un nuevo impulso e interés por el texto renovado del Directorio. Dos podrían ser las aportaciones más inmediatas:

- Se subraya una vez más la importancia de la arquitectura o división cuatripartita del CCE - basada en el Catecismo Romano de Trento y fundamentada en la tradición de la Iglesia - para la transmisión de la fe ${ }^{55}$.

- Una nueva redacción del n. 2267 del CCE sobre la pena de muerte, la cual pasaría a ser considerada "inadmisible, porque atenta contra la inviolabilidad y la dignidad de la persona" ${ }^{\prime 5}$. De ella acabará haciéndose eco el futuro DC, tratándola dentro del apartado "La catequesis y la integridad de la persona", que es considerado como uno de los escenarios socio-culturales contemporáneos de la catequesis (Cf.. DC 379-380).

- La preparación del nuevo Comentario teológico-pastoral al CCE, de cuyos trabajos se ocupó personalmente Mons. R. Fisichella ${ }^{57}$, permitió contactar a diversos expertos y especialistas de catequesis de todo el mundo. Sus contribuciones ayudarían a aquilatar la futura colocación del CCE y su Compendio en el Directorio.

54 Ruiz Arenas, "Conferencia".

55 PCPNE, Commemorazione del $25^{\circ}$ del Catechismo della Chiesa Cattolica (11 de octubre de 2017). Una crónica de los eventos y del contenido de las intervenciones: J. R. Villar, "En el 25 aniversario del Catecismo de la Iglesia Católica", Scripta Theologica 49 (2017) 727-744.

56 Francisco, Discurso del Santo Padre Francisco con motivo del XXV Aniversario del Catecismo de la Iglesia Católica (11 de octubre de 2017). El cambio se realizaba al año siguiente: Congregación para la Doctrina de la Fe, Nueva redacción del n. 2267 del Catecismo de la Iglesia Católica sobre la pena de muerte - Rescriptum "ex audientia SS. Mi" (1 de agosto de 2018).

57 R. Fisichella (ed.), Catechismo della Chiesa cattolica. Testo integrale. Nuovo commento teologico-pastorale, Milano 2017. Esta edición especial actualiza y renueva con una perspectiva pastoral a la anterior: R. Fisichella (ed.), Commento Teologico al Catechismo della Chiesa Cactolica, Casale Monferrato 1993]. PCPNE, Edizione speciale del "Catechismo della Chiesa Cattolica". Monsignor Rino Fisichella (1l de octubre de 2017). 
Sólo unos días después de esta efeméride histórica, del 16 al 17 de octubre, el Co.In.Cat se reunió para estudiar el nuevo borrador y discutir algunos temas de interés para el nuevo Directorio, como son los jóvenes, la cultura digital, la piedad popular y la catequesis para y con las personas con discapacidad ${ }^{58}$.

\subsection{Una nueva edición (2018-2020): el tercer Directorio poscon- ciliar para la Catequesis}

Nos encontramos en la última fase de elaboración y redacción del nuevo DC. Está marcada por una continua dinámica de relectura global del texto, realizada por parte de un grupo reducido de expertos en estrecha colaboración con el PCPNE. No obstante, en esta etapa se continuaron realizando algunas consultas específicas, sobre ciertas temáticas actuales y cruciales para la catequesis, como son la cultura digital.

Los esfuerzos se centraron en la revisión general del texto. Con ella se pretendía dotarlo de unidad interna y una uniformidad redaccional. Pero, sobre todo, proporcionarle esa nueva perspectiva que el papa Francisco había esbozado en la EG para una conversión misionera de la catequesis, propia de la nueva etapa evangelizadora de la Iglesia, y detonante principal de la revisión y actualización del DGC.

Del mismo modo, en este momento se buscó integrar las aportaciones doctrinales y pastorales de la exhortación Gaudete et exsultate, sobre el llamado a la santidad en el mundo actual (2018) 59; y la reflexión de los últimos Sínodos de los Obispos sobre los jóvenes (octubre 2018) y la Amazonía (2019), y sus respectivas exhortaciones post-sinodales, Christus vivit (2019) ${ }^{60}$ y Querida Amazonia (2020) ${ }^{61}$.

58 Ruiz Arenas, "Conferencia”.

59 Francisco, Exhortación apostólica, Gaudete et exsultate, sobre el llamado a la santidad en el mundo actual (19 de marzo del 2018).

60 Francisco, Exhortación apostólica postsinodal, Christus vivit (25 de marzo del 2019) En adelante $C h V$.

61 Francisco, Exhortación apostólica postsinodal, Querida Amazonia (2 de febrero del 2020). 
Todos estos trabajos trajeron consigo una rápida sucesión de ocho borradores, el doble que en las dos etapas anteriores juntas ${ }^{62}$. Con ello, entre los implicados en este proceso de revisión y actualización del DGC irá creciendo una conciencia, cada vez más generalizada, de que el nuevo texto era ya el borrador de una nueva edición.

\subsubsection{Nueva estructura del Îndice general y nueva redacción}

Sobre la base las observaciones de los Miembros de la Plenaria del PCPNE y teniendo en cuenta las aportaciones del Co.In.Cat y los acontecimientos en torno al Aniversario del CCE, el PCPNE trabaja en este último trimestre del año 2017 en la elaboración del quinto borrador. Éste será examinado por un pequeño grupo de expertos, sobre cuyas aportaciones y correcciones se trabajará desde dentro del PCPNE durante el primer trimestre del nuevo año 2018.

En este momento, los cambios más significativos se producen en el octavo y décimo borrador. Los trabajos que condujeron a ellos tendrán que realizarse simultáneamente con la organización y preparación del II Congreso Internacional de Catequesis (Roma, 20-23 de septiembre de 2018), que se celebraría en Roma bajo el título "El Catequista, testigo del misterio", y en el que se estudiaría la segunda parte del CCE ("La celebración del misterio cristiano") ${ }^{63}$.

En el octavo borrador, la estructura del índice general sufre cambios significativos, acercándose ya a la versión definitiva. Además, se realiza una importante la revisión de algunos capítulos, y se puntualizan conceptos fundamentales relativos a la naturaleza de la catequesis y a su relación con la evangelización. Por otro lado, se introducen posteriormente una serie de aportaciones para el desarrollo de las temáticas de la cultura digital, la inculturación y la cultura indígena.

Los trabajos del décimo borrador ocuparán todo el primer semestre del año 2019. Prácticamente se realizan todos ellos dentro del PCPNE, aunque con algunas colaboraciones puntuales externas.

62 Ruiz Arenas, Conferencia”.

63 PCPNE, II Congreso Internacional de Catequesis (20-23 de septiembre de 2018). 
Fundamentalmente, se hace una lectura detallada y una revisión de todo el documento con el fin de unificar el estilo y de eliminar las repeticiones. Además, se revisan las citaciones y las notas, y se actualizan las referencias magisteriales, sobre todo incluyendo las aportaciones para la catequesis de los últimos Documentos. Finalmente, se continúa trabajando en la clarificación de algunos conceptos y términos claves, así como en la redacción y reescritura de ciertos números, que en algunos casos fue prácticamente total ${ }^{64}$.

\subsubsection{Trabajos finales}

Los trabajos de los dos últimos borradores (junio de 2019 - marzo de 2020) tuvieron que compaginarse con la organización y realización de los dos encuentros internacionales de septiembre y noviembre mencionados. Las tareas del Directorio se concentran prácticamente en cuestiones de estilo y de metodología formal: revisión y corrección de las citas y del aparato crítico de notas; elaboración de los índices temáticos y de documentos; preparación de la Introducción y la Conclusión.

Antes de enviar el duodécimo y último borrador a la Congregación para la Doctrina de la fe para las últimas correcciones, procedimiento habitual y último paso antes de la aprobación de cualquier documento, se pide un último parecer a los dicasterios de la Santa Sede para aquellas secciones del texto que son de su competencia, y se realiza una revisión estilística por parte de un experto lingüista italiano.

\subsubsection{Aprobación, publicación y presentación}

Después de introducir las últimas correcciones y las observaciones de la Congregación para la Doctrina de la fe y, tras casi seis años de trabajo, por fin se llega a la tan esperada versión final del texto.

64 Temas relativos al kerigma, el diálogo, la inspiración catecumenal; la formación de catequistas; la pedagogía de la fe y el lenguaje narrativo; la experiencia humana y la belleza; la inculturación, la cultura y sus escenarios; o, finalmente, a "La catequesis en la vida de las personas". 
Un documento que ya no es sólo una revisión y actualización del DGC, como al inicio, sino una nueva edición, la tercera de su género tras el Concilio. El texto contenía demasiadas novedades - de orientación, de perspectiva y planteamiento; contextuales, magisteriales, temáticas, estructurales y redaccionales -, como para seguir considerándose, sin más, como una revisión y actualización del anterior. La estructura y la redacción del DGC, que por tantos años había servido a la organización y orientación de la catequesis, se había vuelto insuficiente y aparecía totalmente renovada.

El Santo Padre, el papa Francisco, lo aprobaba el 23 de marzo de 2020. Su edición oficial en lengua italiana, y publicada simultáneamente por la Libreria Editrice Vaticana (LEV) y San Paolo Edizioni65, era presentada por el PCPNE en la Sala de Prensa de la Santa Sede el 25 de junio, en la memoria litúrgica de santo Toribio de Mogroviejo (1538-1606); un obispo, evangelizador y catequista de origen español y figura señera de la evangelización de América Latina. La edición española salía a la luz el 1 de octubre del mismo año, y era presentada el 19 de noviembre en la Sede de la Conferencia Episcopal Española ${ }^{66}$. En su portada aparece la imagen del mosaico de santo Toribio de Mogroviejo de la Capilla de la Sucesión de la Conferencia Episcopal Española (Madrid).

65 Durante los meses de abril y mayo el PCPNE había estado preparando la Presentación y concordando con las Conferencias Episcopales su traducción a las principales lenguas: español (edición para América Latina y España), portugués (edición para Brasil y Portugal), inglés (edición para USA y Reino Unido), francés y polaco: R. Fisichella, Conferenza Stampa di presentazione del Direttorio per la Catechesi redatto dal Pontificio Consiglio per la Promozione della Nuova Evangelizzazione. Intervento di S.E. Mons. Rino Fisichella (25 de junio de 2020), en: Oficina de Prensa de la Santa Sede

66 Conferencia Episcopal Española, Presentación del nuevo directorio de catequesis (19 de noviembre de 2020). 